\title{
EFEITOS DE APELOS DE RESPONSABILIDADE SOCIOAMBIENTAL E DE INTERESSE DO CONSUMIDOR: UMA ANÁLISE NO SETOR BANCÁRIO
}

\author{
Francisco José da Costa* \\ franzecosta@gmail.com \\ Diana Lúcia Teixeira de Carvalho* \\ dianaluciatc@gmail.com \\ Joaquim Monteiro Reis Pacheco* \\ Joaquim_pacheco@outlook.com
}

*Universidade Federal da Paraíba - PB / Brasil

http://dx.doi.org/10.1590/1413-2311.09716.63814

Recebido em 07/04/2016

Aprovado em 14/03/2017

Disponibilizado em 31/05/2017

Avaliado pelo sistema "double blind review"

Revista Eletrônica de Administração

Editora-chefe: Andrea Oltramari

ISSN 1413-2311 (versão "on line")

Editado pela Escola de Administração da Universidade Federal do Rio Grande do Sul

Periodicidade: Quadrimestral

Sistema Requerido: Adobe Acrobat Reader

\section{RESUMO}

Esse artigo objetivou analisar, comparativamente, as reações de clientes bancários a investimentos centrados no seu interesse e em iniciativas de responsabilidade socioambiental. Visando ter um referencial comparativo por tipo de empresa, foram analisadas ações de bancos e supermercados, na cidade brasileira de João Pessoa. Foi realizada uma revisão teórica que resultou em cinco hipóteses (e três sub-hipóteses), avaliadas por um desenho experimental 2x3. Na pesquisa de campo, foram obtidos dados de 249 respondentes, e as hipóteses foram analisadas pelo teste $t$ de Student e por análise de variância. Os resultados sinalizaram que os consumidores, sem que sejam expostos a estímulos publicitários de responsabilidade socioambiental, têm 
reações mais favoráveis a iniciativas no seu interesse; quando precisam se posicionar diante de estímulos, os investimentos socioambientais são mais valorizados. Quanto à análise por tipo de empresa, os efeitos sobre atitude, preferência e predisposição a recomendar, quando as ações são realizadas por bancos, foram piores em comparação aos supermercados.

PALAVRAS-CHAVE: Responsabilidade socioambiental. Interesse dos clientes. Bancos.

\title{
EFFECTS OF MESSAGE APPEALS OF SOCIO-ENVIRONMENTAL RESPONSIBILITY AND CONSUMER INTERESTS: AN ANALYSIS IN THE BANKING SECTOR
}

\begin{abstract}
This article aimed to analyze, comparatively, the bank customers' reactions to investments focused on their interest and on social and environmental responsibility initiatives, and aimed to further compare the evaluations of actions of bank and supermarkets in the Brazilian city of João Pessoa. Initially, a theoretical review was conducted, which resulted in five hypotheses (and three sub hypotheses), that were evaluated using an experimental $2 \times 3$ factorial design. In the field survey, data from 249 respondents were obtained, and the hypotheses were analyzed by Student's $\mathrm{t}$ test and analysis of variance. The results indicate that consumers, without being exposed to advertising stimuli of social and environmental responsibility, have more favorable reactions to initiatives in their interest; when they have to position themselves facing stimuli, social and environmental investments bring better evaluations. Regarding the analysis by company type, the effects on attitude, preference and willingness to recommend, when associated to banks, were worse evaluated, compared to supermarkets.
\end{abstract}

KEYWORDS: Social and environmental responsibility. Customer interest. Banks.

EFECTOS DE LLAMADAS DE RESPONSABILIDAD SOCIOAMBIENTAL Y EN EL

REAd | Porto Alegre - Edição 86 - Nº 1 - Janeiro / Abril 2017 - p. 179 - 205 


\section{INTERÉS DEL CONSUMIDOR: UN ANÁLISIS EN EL SECTOR BANCARIO}

\section{RESUMEN}

Este artículo tuvo como objetivo analizar comparativamente las reacciones de los clientes bancarios a inversiones enfocadas en su interés y en iniciativas de responsabilidad socioambiental. Para tener una referencia comparativa por tipo de negocio, se analizaron acciones de bancos y supermercados en la ciudad brasileña de João Pessoa. Se llevó a cabo una revisión teórica de la que resultaron cinco hipótesis (y tres sub-hipótesis), evaluadas utilizando un diseño experimental 2x3. En la investigación de campo, se obtuvieron datos de 249 encuestados, y las hipótesis se analizaron mediante el $t$ de Student y el análisis de la varianza. Los resultados señalaron que los consumidores, sin estar expuestos a los estímulos publicitarios de responsabilidad social y ambiental, tienen reacciones más favorables a las iniciativas de su interés; cuando son expuestos a los estímulos, las inversiones sociales y ambientales se valoran más. En cuanto al análisis por tipo de empresa, los efectos sobre la actitud, la preferencia y disposición a recomendar, cuando las acciones son realizadas por los bancos, fueron peor evaluados en comparación con los supermercados.

PALABRAS CLAVE: Responsabilidad socio-ambiental. Interés de los clientes. Bancos.

\section{INTRODUÇÃO}

No contexto empresarial brasileiro, o setor bancário é um dos que mais se destacam em termos de eficiência geral (atestada pela elevada lucratividade), assim como em termos de desconfiança social. Apesar dos seus lucros, os bancos são empresas de altos investimentos em qualidade de atendimento e responsabilidade socioambiental (CRISÓSTOMO, FREIRE, SANTOS, 2012), ou seja, além dos lucros, bancos também são destacados pelo aperfeiçoamento do atendimento e pelo dispêndio em ações no interesse social.

Ainda assim, na visão dos autores desse artigo, essas empresas não conseguiram se 
dissociar de uma imagem relacionada a problemas de ética e exploração da sociedade. Isso parece se reafirmar quando observamos que os 'lucros dos bancos' são temas recorrentemente tratados por políticos em épocas de campanhas políticas (na exploração pelo marketing eleitoral de uma aparente desconfiança social quanto a essas instituições), assim como nos argumentos das lideranças sindicais dos trabalhadores bancários, nas recorrentes greves do setor.

Nesse artigo, enfocamos em investimentos bancários pra uma avaliação comparativa, e os efeitos desses investimentos nas percepções de consumidores. Tomamos duas referências para efeito de análise dos investimentos realizados: aqueles empreendidos no interesse do consumidor, associados, por exemplo, a ações de aprimoramento de qualidade de atendimento, a políticas de garantias, melhorias de instalações etc.; e aqueles empreendidos em responsabilidade socioambiental, em ações, por exemplo, orientadas a causas humanitárias (voltadas a pessoas carentes ou em situação de risco, como custeio de abrigos, doações a ONGs...) ou a causas ambientais (como ações de reciclagem, gasto em reflorestamento, contribuição com a causa animal...).

O texto se alinha, portanto, a uma série de estudos que já analisaram os potenciais efeitos benéficos dos investimentos em ações de responsabilidade socioambiental (RSA) (e.g. SEN, BHATTACHARYA, KORSCHUN, 2006; BHATTACHARYA, KORSCHUN, SEN, 2009; PELOZA, CHANG, 2011). Esses estudos, de maneira universal, sinalizam que investimentos em RSA de empresas em geral, e bancos em particular, alcançam o benefício de promover nos consumidores comportamentos relevantes para as empresas, como atitude mais positiva, confiança, intenções de lealdade, intenções de boca a boca, e, inclusive, predisposição a pagar um preço mais elevado por produtos de empresas que se associam a essas causas.

Não há dúvida, portanto, da relevância e do resultado positivo desse tipo de ação, o que, efetivamente, é um dos motivadores do largo investimento realizado por vários tipos de empresas. Porém, quando se compreende que os investimentos empresariais realizados para geração de resultados positivos são de variados tipos, e que as empresas precisam priorizar àqueles que são mais relevantes, um questionamento que emerge diz respeito à prioridade de ações de RSA frente àquelas que as empresas precisam realizar no interesse direto do consumidor. Com esse estudo pretendemos responder à seguinte questão central: qual tipo de iniciativa de responsabilidade social tem mais impacto na percepção dos consumidores do setor bancário em relação a empresas de outros setores?

REAd | Porto Alegre - Edição 86 - N 1 - Janeiro / Abril 2017 - p. 179 - 205 
Para efeito de ordenamento do trabalho, em termos de lançamento de hipóteses e sua discussão à luz da pesquisa empírica realizada, lançamos como primeiro objetivo do trabalho analisar a avaliação dos consumidores acerca de investimentos no seu interesse ou em iniciativas de RSA. O alcance desse objetivo permitirá compreender se há variação de preferência e avaliação, e caso haja, qual a natureza dessas variações, o que se alinha aos estudos de McDonald e Lai (2011) e Pérez e Rodríguez del Bosque (2015b). Definimos ainda como segundo objetivo do estudo proceder a uma comparação desses resultados quando são realizados por bancos ou por outro tipo de empresa (e.g. MATTILA, HANKS, KIM, 2010; PÉREZ, RODRÍGUEZ DEL BOSQUE, 2014, 2015b; ANDREU, CASADO-DÍAZ, MATTILA, 2015). Tomamos como referência comparativa as empresas supermercadistas, que não parecem gerar a mesma desconfiança social que os bancos, mas que têm largos investimentos em marketing e em responsabilidade socioambiental.

Na construção do trabalho, primeiramente, desenvolvemos uma revisão da literatura, que indicou uma visão geral do estado da arte sobre o tema e viabilizou o lançamento das hipóteses do estudo. Na sequência, apontamos as principais decisões e ações metodológicas do trabalho de campo, cujos resultados são mostrados e debatidos na seção seguinte do artigo. A última seção traz as considerações finais do estudo.

\section{REVISÃO TEÓRICA E HIPÓTESES}

Nesse item são apresentadas as discussões teóricas que fundamentam as hipóteses do nosso estudo. Desse modo, inicialmente, debatemos sobre as reações dos consumidores a tipos

diferentes de iniciativas de RSA, e, em seguida, sobre os investimentos de RSA realizados particularmente por bancos.

\section{1 Responsabilidade social nas organizações}

A ideia de que as empresas têm diversas responsabilidades para com todos os stakeholders remete à noção de Responsabilidade Social Corporativa (RSC). Conforme Carroll (1991), desde a década de 1950 se fala a respeito da responsabilidade da empresa para com a sociedade na qual está inserida, mas foi apenas no final dos anos de 1970, com a criação de 
legislações sociais por meio de agências de proteção do meio ambiente, de segurança trabalhista e de proteção ao consumidor que a noção acerca da responsabilidade corporativa se ampliou e ganhou força.

Entretanto, embora identifiquem diversas contribuições teóricas para ao longo dos anos, Schwartz e Carroll (2008) destacam que uma definição comum de RSC continua pouco clara, sendo inerentemente vaga e ambígua, tanto na teoria quanto na prática. McDonald e Lai (2011), por sua vez, ressaltam que mesmo que haja uma variedade de definições de RSC, é amplamente reconhecido que, juntamente com a lucratividade, obrigações societais e ambientais devem ser incorporadas nas responsabilidades empresariais.

Com efeito, Vaaland, Heide e Grønhaug (2008) observam que dentre as variadas definições de RSC são enfatizados os conceitos de benefício corporativo e de stakeholders, bem como se destacam os fenômenos sociais, ambientais e éticos. RSC tem o potencial de criar fortes relações entre as organizações e seus stakeholders, por meio de atividades que englobam uma variedade de iniciativas (PELOZA, CHANG, 2011). Diante disso, é necessário compreender como os consumidores, um dos principais stakeholders das organizações, percebem as iniciativas de responsabilidade com enfoque socioambiental (RSA), de modo que se desdobrem em benefício corporativo, o que é discutido a seguir.

\section{2 Posicionamento de consumidores em relação a ações de RSA}

De acordo com Bhattacharya e Sen (2004), os clientes de uma empresa representam um grupo de stakeholders que parece ser fortemente sensível a iniciativas de responsabilidade socioambiental, e as indicações são de que há uma relação positiva entre as ações de RSA de uma empresa e as reações dos consumidores acerca da imagem dessa empresa e de seus produtos. Porém, a configuração dessas reações não parece ser universal por setor empresarial nem por tipo de ação empreendida. Assim, é provável que uma ação de apoio a uma causa (ajuda a uma escola do bairro, por exemplo) tenha um efeito diferenciado se for empreendida, por exemplo, por um supermercado ou por um banco. Além disso, e considerando a ampla variedade de atividades de RSA, é possível supor que nem todas sejam percebidas de maneira igualmente positiva, algumas das quais podendo sequer serem vistas positivamente por todos os stakeholders (PELOZA, SHANG, 2011).

REAd | Porto Alegre - Edição 86 - N 1 - Janeiro / Abril 2017 - p. 179 - 205 
Essa é a razão pela qual a temática sobre a percepção dos clientes das atividades de RSA tem atraído o interesse de acadêmicos e gestores. É evidente a necessidade de se assegurar que a imagem gerada pelas ações impulsione suficientemente os benefícios relacionados ao cliente, como satisfação, intenção de recompra e pretensão de recomendar a empresa a outros consumidores (PÉREZ, RODRÍGUES DEL BOSQUE, 2015a).

Bhattacharya, Korschun e Sen (2009) propuseram um modelo conceitual que explica como a responsabilidade socioambiental proporciona vários benefícios (funcional, psicológico e de valores) para os stakeholders individuais. Os benefícios funcionais são aqueles tangíveis ou diretamente relacionados com as características do produto ou serviço; os benefícios psicológicos se relacionam ao bem-estar psicológico e social do indivíduo; já os benefícios de valor dizem respeito aos atributos que afirmam os valores do indivíduo, e são estados finais de importância para o consumidor.

Acreditamos que, pela natureza da empresa, os investimentos em RSA precisam se justificar para algo além, e complementar, do benefício social gerado (YOON, GIIRHANCANLI, SCHWARZ, 2006). Assim, a suposição aqui é de que, além do benefício social gerado, as ações dessa natureza geram nos consumidores reações e atitudes favoráveis, sendo esse um ganho complementar e um incentivo para as empresas. As ações de RSA têm seu custo, e é relevante buscar entender se esse custo, pelos resultados que gera, tem efeito mais ou menos positivo na visão dos consumidores, se comparado aos investimentos que são feitos diretamente no interesse dos consumidores, como por exemplo aqueles orientados a melhoria do atendimento, a ações de relacionamento etc.

Assim, nesse estudo, optamos por comparar o efeito sobre as avaliações de consumidores mediante, em termos operacionais (da pesquisa de campo), três tipos de investimentos: em causas humanitárias e altruístas (diretamente em prol das pessoas), em causas ambientais, e centradas no consumidor. Por essa configuração, é possível supor que haja diferentes reações dos consumidores no que concerne às suas atitudes, preferências e lealdade, quando eles são apresentados a estímulos que representem cada uma dessas iniciativas.

De acordo com McDonald e Lai (2011), embora poucas sejam as pesquisas que comparam o impacto relativo de diferentes iniciativas de RSA diante da avaliação do consumidor, há estudos que têm classificado as preocupações e preferências dos consumidores em termos dessas iniciativas, identificando uma relação de influência positiva do RSA nas 
atitudes dos consumidores, por exemplo. Entretanto, sobre reações às iniciativas distintas de RSA, quando comparadas às iniciativas centradas no consumidor, há evidências de que os consumidores, em geral, valorizam mais positivamente àquelas voltadas ao seu interesse (PÉREZ, RODRÍGUEZ DEL BOSQUE, 2015b). É possível supor que essa seja também a realidade brasileira e, nesse sentido, enunciamos a primeira hipótese, abaixo indicada:

- H1 - Em geral, os consumidores atribuem maior importância aos investimentos realizados por empresas no seu interesse que nos investimentos em responsabilidade socioambiental, sejam esses vinculadas a causas humanitárias ou ambientais.

Além da percepção de importância comparativa dos tipos de atividades e investimentos, e considerando outras avaliações da literatura especializada, para efeito de análise, nesse estudo, tomamos por recorte adicional as reações relacionadas à atitude, à preferência do consumidor pela empresa, e à predisposição dos consumidores a recomendar a empresa (essas últimas como referências associadas ao nível de lealdade do consumidor).

Em termos de atitudes, McDonald e Lai (2011), por exemplo, sugerem que os consumidores respondem mais favoravelmente a estratégias que são em prol dos seus interesses do que àquelas que são direcionadas à comunidade, como iniciativas filantrópicas ou ambientais. Também segundo o estudo realizado por Pomering e Dolnicar (2006) com consumidores de bancos australianos, dentre oito tipos de investimentos apresentados, foram consideradas mais positivamente as iniciativas que eram centradas nos interesses dos consumidores em detrimento de ações de cunho humanitário ou ambiental.

Há ainda algumas pesquisas desenvolvidas (e.g. POMERING, DOLNICAR, 2006; MCDONALD, RUDLE-THIELE, 2008; MCDONALD, LAI, 2011) que revelam que iniciativas centradas no consumidor, ou seja, que diretamente o beneficiam, provavelmente geram um maior impacto na avaliação global do consumidor do que as iniciativas de RSA com foco em ações de benefício social. Esse entendimento levantou nos autores desse artigo o questionamento sobre a pertinência dessa conclusão em nível de Brasil, sob a suposição preliminar de que, também nesse país, o comportamento dos consumidores segue a mesma tendência. Diante desses argumentos, colocamos as seguintes hipóteses:

- $\mathrm{H} 2$ - Os consumidores desenvolvem atitudes mais favoráveis a empresas que enfatizam os investimentos no seu interesse do que por empresas que enfatizam investimentos em causas 
humanitárias e ambientais.

- H3 - Os consumidores desenvolvem maior preferência por empresas que enfatizam os investimentos no seu interesse do que por empresas que enfatizam investimentos em causas humanitárias e ambientais.

- H4 - Os consumidores declaram maior predisposição a dar recomendações de empresas que enfatizam os investimentos no seu interesse do que de empresas que enfatizam investimentos em causas humanitárias e ambientais.

Entretanto, entendemos que não apenas o tipo de iniciativa resulta em diferentes reações dos consumidores, mas que também o tipo de empresa impacta na avaliação dos consumidores. No item seguinte tratamos dessa questão com foco no setor de instituições financeiras.

\subsection{Instituições bancárias e ações de RSA}

Iniciativas de RSA são largamente utilizadas pelas instituições financeiras, provavelmente em resposta ao fato de esse tipo de empresa ser bastante pressionado pelo público em geral para que seja socialmente responsável, tendo em vista ser um setor de alta lucratividade (MCDONALD, RUDLE-THIELE, 2008). Esse parece ser o fator de motivação de várias pesquisas acadêmicas que têm verificado os impactos de ações de RSA nas avaliações ou reações dos consumidores do setor (e. g. POOLTHONG, MANDHACHITARA, 2009; KHAN e outros, 2014; KHAN, FERGUSON, PÉREZ, 2015) e na imagem das instituições bancárias (e. g. PÉREZ, RODRÍGUEZ DEL BOSQUE, 2012; SCHARF, FERNANDES, KORMANN, 2012).

Instituições financeiras são empresas que, em geral, inspiram ceticismo e suspeita acerca das informações que veiculam, inclusive em relação à propaganda de seus produtos e serviços (MATTILA, HANKS, KIM, 2010). Nesse sentido, a desconfiança e o ceticismo do consumidor em relação a uma empresa e suas atividades de RSA podem moderar a efetividade das avaliações dessas iniciativas (YOON, GÜRHAN-CANLI, SCHWARZ, 2006; DU, BHATTACHARYA, SEN, 2010).

Observamos, na literatura sobre o impacto de iniciativas de RSA em consumidores de bancos, que algumas pesquisas compararam as avaliações de consumidores em relação às 
comunicações de um mesmo tipo de ação de RSA, comparando tipos de empresas diferentes (sendo pelo menos uma deles uma instituição financeira). A pesquisa de Mattila, Hanks e Kim (2010), por exemplo, comparou a atitude dos consumidores em relação ao anúncio e à reputação da empresa mediante mensagens de RSA idênticas, mas de tipos de empresas diferentes (banco e telefonia), e mostrou que as mensagens relacionadas ao banco obtiveram resultados que evidenciaram melhores níveis de atitude (quando o anúncio era da empresa de telefonia o impacto da mensagem foi negativo ou mínimo).

Já a pesquisa de Pérez e Rodríguez del Bosque (2015b) partiu da suposição de que consumidores de bancos comerciais e de poupança processam de maneira distinta as informações e que as consequências das dimensões de imagem de RSA na lealdade seriam, também, diversas; mas essa suposição não se confirmou no estudo. Esse resultado converge com a pesquisa de Pérez e Rodríguez del Bosque (2014), que, da mesma forma, comparou diferenças entre bancos comerciais e de poupança, e verificou que os clientes de instituições bancárias são mais centrados nos seus interesses, e que, portanto, não há diferença na importância que eles atribuem a iniciativas de RSA.

Em uma perspectiva comparativa, tivemos ainda a pesquisa de Andreu, Casado-Díaz e Mattila (2015), que operacionalizou as reações dos consumidores de bancos como dependentes de três fatores: tipo de estímulo de RSA, apelo contido na mensagem e tipo de serviço. Nesse caso, os autores utilizaram estímulos relacionados ao meio ambiente e aos funcionários, com apelos de natureza racional e emocional, sobre serviços utilitarista (banco) e hedônico (restaurante).

No conjunto das análises, observamos nessas pesquisas a indicação de que, a depender do tipo de empresa e de serviço prestado (se consideramos que bancos comerciais e de poupança são ambas instituições da mesma natureza, embora com variação na oferta de serviço principal), as iniciativas de RSA podem ter um impacto diferenciado nas avaliações dos consumidores. Considerando especificamente a realidade brasileira, também nos parece provável que, se compararmos o comportamento dos consumidores em relação às iniciativas de RSA vinculadas a instituições financeiras e a outro tipo de empresa, deve haver diferença entre os resultados. Porém, dada a desconfiança social quanto aos bancos, é possível supor que as avaliações sejam piores para os bancos que para outras empresas.

Neste mesmo alinhamento, nessa pesquisa preferimos desenvolver uma análise para 
confrontar as avaliações de iniciativas de RSA de bancos comparando com outro setor. Assim, optamos por operacionalizar uma comparação com supermercados, que são empresas igualmente muito presentes na vida das pessoas em geral e que investem bastante em relacionamento com os

clientes e em RSA. Adotamos empresas do tipo supermercado também sob a suposição de que sua imagem e sua reputação podem ser influenciadas pelas ações de RSA (DU, BHATTACHARYA, SEN, 2010). Mantendo as mesmas causas de referência (centrada no consumidor, humanitária e ambiental) para os dois tipos de empresas, comparando e considerando a discussão anterior, lançamos as seguintes hipóteses:

- H5 - As avaliações dos consumidores variam por tipo de empresa, sendo mais favoráveis aos supermercados que aos bancos.

○ H5a - Os consumidores desenvolvem atitudes mais favoráveis aos supermercados que aos bancos, independente do investimento anunciado.

○ $\mathrm{H} 5 \mathrm{~b}$ - Os consumidores desenvolvem maior preferência por ofertas de supermercados que dos bancos, independente do investimento anunciado.

○ H5a - Os consumidores desenvolvem predisposições à recomendação maiores nos supermercados que nos bancos, independente do investimento anunciado.

Considerando o conjunto de hipóteses lançadas, decidimos empreender um estudo de campo, cujos detalhes estão apontados a seguir.

\section{PROCEDIMENTOS METODOLÓGICOS}

Neste item apresentamos as decisões metodológicas que direcionaram o trabalho de campo. Optamos por uma pesquisa de desenho experimental, a fim de verificar os efeitos de três tipos de investimentos de empresas (no interesse de clientes, em causas ambientais e humanitárias) na avaliação dos consumidores de bancos e supermercados, comparativamente. $\mathrm{Na}$ sequência, expomos, ordenadamente, as decisões de mensuração, de desenho da pesquisa e da análise dos dados.

Para coleta de dados, decidimos utilizar um questionário impresso estruturado em duas laudas. Na primeira lauda, o questionário continha um conjunto de afirmações dispostas em 
formato de escala de concordância tipo Likert com 11 pontos, com variação entre 0 e 10 . O conteúdo dessas afirmações buscou mensurar a preferência e o nível de importância atribuído pelo respondente em relação a empresas (em geral) que desenvolvem ações relacionadas às causas socioambiental nos dois tipos de referência no estudo (humanitária e ambiental), e no interesse do consumidor. Ainda nessa primeira parte do questionário foram acrescentadas questões socioeconômicas e demográficas (gênero, idade, estado civil, nível de formação e renda).

A segunda lauda do instrumento apresentava os estímulos referentes a cada tipo de investimento das empresas, vinculados a um banco e a um supermercado. Assim, para efeito comparativo, foram criados anúncios idênticos em texto e imagem, assim como no nome das empresas (Bom Sucesso) e no seu slogan (Semeando o futuro) para ambos os tipos de empresa. Essa decisão gerou seis cenários diferentes, um para cada tipo de instituição e ação, constituindose um experimento fatorial 2x3. O Quadro 1 contém um exemplo de anúncio elaborado, por tipo de empresa e de causa.

Quadro 1 - Exemplo de anúncio do experimento

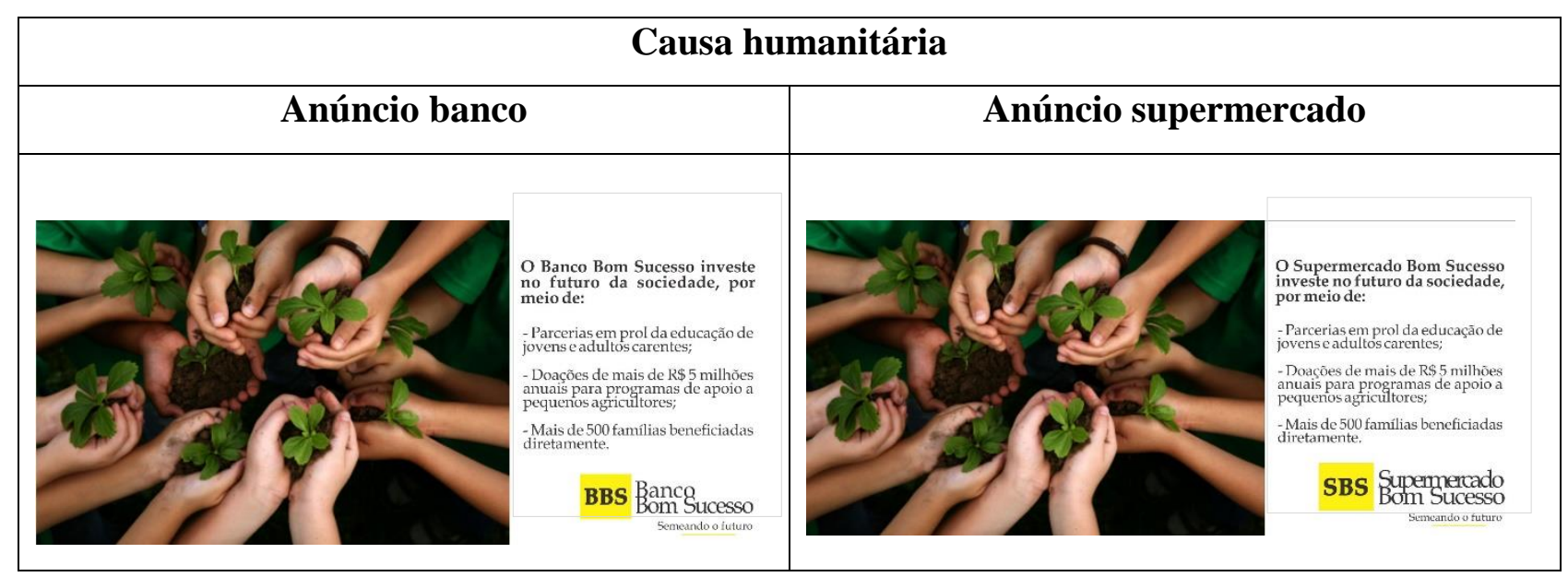

Fonte: Elaborado pelos autores

Os demais anúncios seguiam a mesma lógica de apresentação, em imagem, nome da empresa e slogan. Foram adaptados apenas os textos para cada causa, ou seja, nos anúncios do banco e do supermercado, relativos à causa ambiental, o texto era: "O Banco (ou Supermercado) Bom Sucesso investe para um futuro melhor, por meio de: parcerias com instituições de educação e preservação ambiental; Mais de R \$ 5 milhões disponíveis como fundo de apoio institucional; 
Mais de 50 cidades com novos programas de reflorestamento e coleta seletiva”. Em seguida, o nome da empresa, Banco Bom Sucesso ou Supermercado Bom Sucesso, diferenciava o tipo de empresa, com slogan idêntico. O mesmo ocorreu nos anúncios de investimento no interesse do consumidor, que possuíam o seguinte texto: "O Banco (ou supermercado) Bom Sucesso investe no crescimento dos seus clientes, por meio de: pesquisas com nossos clientes para melhoria constante dos nossos serviços; Mais de $\mathrm{R} \$ 5$ milhões aplicados em treinamento e novas tecnologias; Crescimento de 90\% no número de clientes satisfeitos".

Após a apresentação do anúncio, o respondente era solicitado para avalia-lo de forma geral, por meio de três itens de diferencial semântico de 11 pontos ( 0 a 10$)$, com extremos entre 'muito ruim' e 'muito bom'; 'negativo' e 'positivo'; e 'desfavorável' e 'favorável'. Esses itens permitiram mensurar o construto 'atitude em relação à causa'. Os demais construtos (preferência pela empresa e predisposição a recomendar a empresa), foram medidos por meio de escalas phrase completion, de 11 pontos (de 0 a 10). Para o construto 'preferência pela empresa', tivemos o seguinte enunciado "Se eu precisasse de um serviço como o da empresa BBS, independente de eu ser cliente de outras empresas com os mesmos serviços, a chance de eu consultar diretamente a empresa, tendo em vista seu anúncio, seria...”; os extremos da escala eram 'muito pequena (0) até 'muito grande (10). Já para o construto 'predisposição a recomendar a empresa', tivemos o enunciado "Se alguém me pedisse uma sugestão de (banco ou supermercado), a chance de eu recomendar o BBS seria:..."; os extremos da escala foram os mesmos do construto anterior.

Os dados foram coletados de maneira presencial, sendo os questionários aplicados em diversas localidades de uma cidade do Nordeste brasileiro, como Igrejas, universidade, supermercados, bancos e outras empresas varejistas, a fim de garantir uma diversidade de respondentes. Foram respondidos 249 questionários, dos quais 129 eram relativos ao banco (44 da causa humanitária, 40 da causa ambiental e 45 da causa centrada no consumidor) e 120 ao supermercado (39 da causa humanitária, 43 da causa ambiental e 38 da causa centrada no consumidor). Essa distribuição da amostra por estímulo foi bem equilibrada, o que garante boas condições de análise.

Referente à análise dos dados, inicialmente procedemos ao teste da hipótese $\mathrm{H} 1$, mensurada a partir dos dados oriundos da primeira parte do questionário. Assim, além da extração das medidas de posição (média e quartis), testamos a hipótese por meio do teste $\mathrm{t}$ de Student. Dos dados resultantes da segunda parte do questionário, que foram usados para a 
avaliação dos estímulos, realizamos inicialmente uma análise fatorial exploratória para averiguar a adequação fatorial dos itens do construto latente 'atitude'. Isso permitiu executarmos a análise das demais hipóteses (H2, H3, H4, H5, H5a, H5b e H5c), que, por estarem associadas a um experimento fatorial $2 \times 3$, foram avaliadas por análise de variância (ANOVA) para este tipo de desenho experimental. Foi procedida ainda a extração das medidas de posição (média e quartis) para cada construto (atitude, preferência e recomendação) por empresa e por estímulo, o que permitiu comparar diferenças entre as medidas de acordo com as suas magnitudes.

Os procedimentos foram efetuados de acordo com a literatura especializada (CONOVER,1980; COSTA, 2011; HAIR JR e outros, 2013), e operacionalizados com o uso do pacote estatístico SPSS. No item seguinte temos os resultados do estudo e a discussão das hipóteses.

\section{RESULTADOS}

Neste item apresentamos os resultados do estudo de campo desenvolvido. Ordenadamente, apresentamos os procedimentos e resultados do teste da hipótese que envolvia medidas gerais. Na sequência, analisamos os resultados das medidas geradas com as empresas e os estímulos. Ao final, apresentamos uma discussão dos resultados.

\subsection{Descrição da amostra}

Em termos de caracterização da amostra, tivemos 58,2\% dos respondentes do gênero feminino e 41,8\% do gênero masculino, com predominância do estado civil 'solteiro' (61,8\%). Quanto ao grau de instrução, 60,6\% da amostra indicaram possuir 'ensino superior (completo ou incompleto)', e, do total, 18,5\% revelaram ter 'pós-graduação'. A maioria dos respondentes declarou 'renda familiar' entre R\$1.000 e R\$3.000 (44,6\%), e 'idade' entre 21 e 31 anos (42,6\%). Mediante o perfil da amostra, é possível entendermos que há adequada heterogeneidade para viabilizar as análises das relações entre as hipóteses apresentadas do estudo.

\subsection{Análise das medidas gerais}


Conforme indicado no método, na primeira parte do instrumento de pesquisa tivemos variáveis que questionavam a preferência do consumidor por ações de empresas (em geral) em favor de causas de responsabilidade social (humanitária), de responsabilidade ambiental, e de investimento centrado no seu interesse direto. Também questionamos o nível de importância atribuída pelo respondente a esses três tipos de ações.

Os resultados mostrados na primeira parte da Tabela 1 indicam que, em média, os consumidores declaram menor preferência por consumir produtos de empresas com investimentos em ações de responsabilidade ambiental, tanto em relação a causas humanitárias $(\mathrm{t}(247 \mathrm{gl})=-18,44, \mathrm{p}<0,001)$ quanto em relação aos investimentos centrados no consumidor $(\mathrm{t}(247$ $\mathrm{gl})=-17,66, \mathrm{p}<0,001)$. Analisando a magnitude das medidas de posição, verificamos que as diferenças estão evidenciadas também (além a média) nos quartis. Os níveis da preferência declarada por consumir produtos de empresas que investem em causas humanitárias e em favor do consumidor são os mesmos, conforme se observa em média $(\mathrm{t}(246 \mathrm{gl})=0,47, \mathrm{p}=0,641)$ e nas demais medidas de posição (os quartis).

Tabela 1 - Resultados da primeira parte do instrumento

\begin{tabular}{|c|c|c|c|c|c|}
\hline \multirow[b]{2}{*}{ Variáveis } & \multirow[b]{2}{*}{ Média } & \multirow{2}{*}{$\begin{array}{c}\text { Desvio } \\
\text { padrã } \\
0\end{array}$} & \multicolumn{3}{|c|}{ Quartis } \\
\hline & & & 1 & 2 & 3 \\
\hline \multicolumn{6}{|l|}{ Posição pessoal } \\
\hline $\begin{array}{l}\text { Prefiro consumir produtos de empresas que promovam ações } \\
\text { de proteção ambiental (sustentabilidade, reciclagem, etc.). }\end{array}$ & 5,73 & 2,52 & 4,00 & 5,00 & 8,00 \\
\hline $\begin{array}{l}\text { Prefiro consumir produtos de empresas que ajudem as pessoas } \\
\text { (apoio a ONGs, doação de parte do valor do produto, etc.). }\end{array}$ & 8,76 & 1,61 & 8,00 & 9,00 & 10,00 \\
\hline $\begin{array}{l}\text { Prefiro consumir produtos de empresas que respeitam o } \\
\text { consumidor (garantia, bom atendimento etc.). }\end{array}$ & 8,73 & 1,79 & 8,00 & 9,00 & 10,00 \\
\hline
\end{tabular}

Importância de ações

\begin{tabular}{|c|c|c|c|c|c|}
\hline $\begin{array}{l}\text { Penso que as empresas devem contribuir com projetos em } \\
\text { ações ambientais (proteção animal, produção sem poluentes, } \\
\text { reflorestamento etc.). }\end{array}$ & 4,62 & 2,80 & 2,00 & 5,00 & 7,00 \\
\hline
\end{tabular}




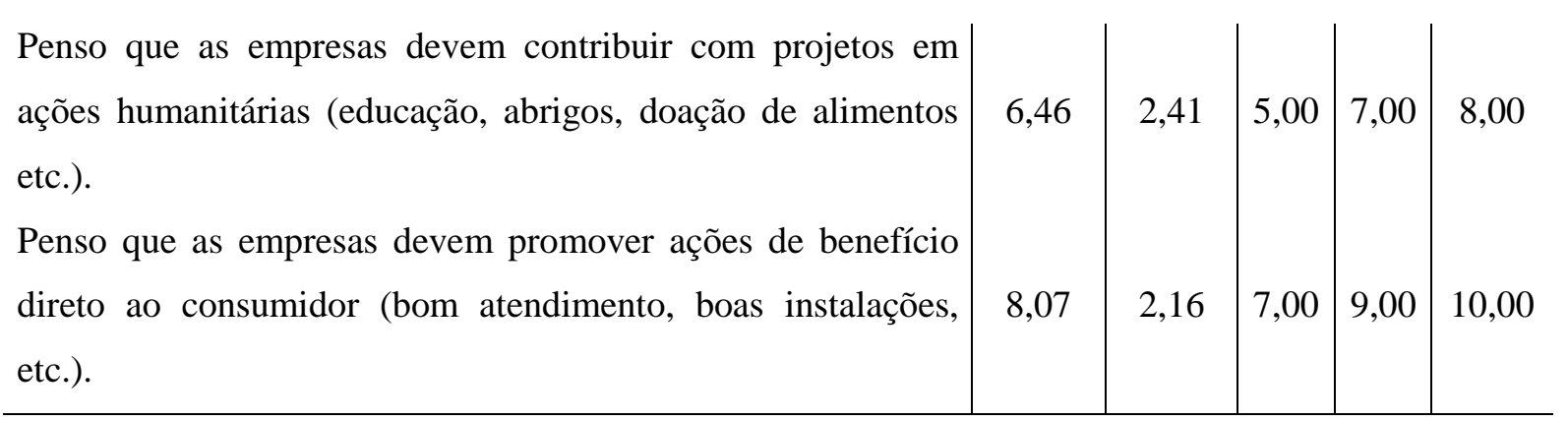

Fonte: Dados da pesquisa

Verificando a magnitude dos valores extraídos, observamos que as medidas de posição central (média e mediana) sinalizam um nível de baixo a moderado em relação à preferência por consumir produtos de empresas que desenvolvem ações ambientais (as medidas ficaram em torno da posição intermediária da escala). Já nas duas demais variáveis, observamos que, nas medidas extraídas, a preferência por consumidor de empresas que investem em causas humanitárias e centradas no consumidor são sempre elevadas (próximas do extremo superior da escala).

Com relação à importância das ações, os resultados da Tabela 1 sinalizam (em sua segunda parte) que os consumidores atribuem um nível mais baixo de importância às causas ambientais em relação às causas humanitárias $(\mathrm{t}(248 \mathrm{gl})=-10,19, \mathrm{p}<0,001)$ e às ações centradas no consumidor $(\mathrm{t}(246 \mathrm{gl})=-16,64, \mathrm{p}<0,001)$. Tivemos ainda evidências de que a importância atribuída às causas de interesse humanitário é menor, em média, que a importância dada às ações no interesse do consumidor $(\mathrm{t}(246 \mathrm{gl})=-9,20, \mathrm{p}<0,001)$.

Pelos valores das medidas de posição vemos que somente temos um nível elevado de importância para ações que são no interesse dos consumidores. Nas ações humanitárias observamos medidas de posição em um nível moderado, sendo destacado que a importância atribuída às questões ambientais ficou já em um nível baixo (mais próximo do extremo inferior da escala).

Esses resultados confirmam a hipótese $\mathrm{H} 1$, e reafirmam que, de fato, os consumidores em geral dão maior importância àqueles investimentos realizados no seu interesse enquanto clientes, em comparação aos investimentos em ações de responsabilidade socioambiental. O resultado da primeira parte indica uma confirmação parcial (e preliminar) da hipótese H3, relativa à preferência dos consumidores. No entanto, e considerando o enunciado da hipótese, sua avaliação mais adequada foi feita pela análise dos resultados do procedimento experimental, detalhado 
abaixo.

\subsection{Análise das hipóteses}

Conforme indicado no método, a segunda parte do questionário contemplou itens para medição dos construtos de referência: atitudes, preferência e predisposições à recomendação. Inicialmente, tivemos três itens para avaliação das atitudes dos respondentes em relação aos anúncios expostos. A suposição era de que os itens mediam o construto latente 'atitude em relação ao anúncio’ em uma perspectiva de mensuração latente refletiva (COSTA, 2011).

Assim, tomando toda a amostra, este conjunto de itens foi submetido à análise fatorial exploratória para verificação da adequação fatorial, e foi ainda extraído o coeficiente alpha de Cronbach para análise de consistência interna. Os resultados mostraram adequação dos itens na mensuração do construto latente (variância extraída de 0,793; menor escore fatorial de 0,856; coeficiente alpha de 0,868), o que viabilizou a sua agregação em uma única variável representativa do construto (adotamos a média dos escores por respondente). Os resultados mostrados na Tabela 2 apontam que, em geral, a atitude dos respondentes foi bastante positiva, com o menor dos quartis (em cada observação e em geral), já próximo de 7,0.

Tabela 2 - Medidas de atitudes

\begin{tabular}{l|c|c|c|c|c|c}
\hline \multicolumn{1}{c|}{ Variáveis } & Escores & \multirow{2}{*}{\begin{tabular}{c}
\multirow{2}{*}{ fatoriais } \\
\end{tabular}} & & Desvio & \multicolumn{3}{|c}{ Quartia } \\
\cline { 5 - 7 } & & & padrão & $\mathbf{1}$ & $\mathbf{2}$ & $\mathbf{3}$ \\
\hline Anúncio muito ruim/muito bom & 0,856 & 7,74 & 2,26 & 6,66 & 7,77 & 10,00 \\
Anúncio negativo/positivo & 0,931 & 7,95 & 2,37 & 6,66 & 8,87 & 10,00 \\
Anúncio desfavorável/favorável & 0,882 & 7,88 & 2,45 & 6,66 & 8,88 & 10,00 \\
Medida geral de atitude & - & 7,85 & 2,01 & 6,66 & 8,15 & 9,26 \\
\hline
\end{tabular}

Fonte: Dados da pesquisa

Estes resultados permitiram avaliar as hipóteses $\mathrm{H} 2$ e $\mathrm{H} 5 \mathrm{a}$, levando em conta a natureza dos investimentos e o tipo de empresa. Procedemos então à extração dos resultados da análise de variância do experimento fatorial $2 \times 3$, e o resultado geral mostrou que há uma diferença 
estatística de nível marginal gerada pelo tipo de empresa $(F(1,247 \mathrm{gl})=3,20, \mathrm{p}=0,075)$, e uma diferença mais significativa em nível de estímulo $(\mathrm{F}(2,247 \mathrm{gl})=4,68, \mathrm{p}=0,010)$.

Concernente às causas, a evidência que temos é de que a diferença mais pronunciada é devida à maior magnitude da atitude formada pelos anúncios para as causas que envolvem responsabilidade socioambiental, em comparação com o anúncio que somente enfatiza o interesse do consumidor. As medidas de posição extraídas demonstram de forma clara que, ao contrário do que supôs a hipótese $\mathrm{H} 2$, efetivamente, o anúncio com causa somente no interesse do consumidor gerou medidas sempre mais baixas, em média e nos quartis. Esse resultado é apresentado na Tabela 3.

Tabela 3 - Medidas de atitudes por empresa e causa

\begin{tabular}{|c|c|c|c|c|c|c|}
\hline \multirow{2}{*}{$\begin{array}{l}\text { Tipo de } \\
\text { empresa }\end{array}$} & \multirow{2}{*}{ Causa } & \multirow{2}{*}{ Média } & \multirow{2}{*}{$\begin{array}{l}\text { Modelo } \\
\text { padrão }\end{array}$} & \multicolumn{3}{|c|}{ Quartis } \\
\hline & & & & 1 & 2 & 3 \\
\hline \multirow{4}{*}{ Bancos } & Causa Humanitária & 8,32 & 1,84 & 7,50 & 8,71 & 10,00 \\
\hline & Causa Ambiental & 7,65 & 2,42 & 6,67 & 8,71 & 9,26 \\
\hline & Centrado no & 6,96 & 2,15 & 5,56 & 7,22 & 8,89 \\
\hline & Total & 7,64 & 2,19 & 6,67 & 8,15 & 9,26 \\
\hline \multirow{4}{*}{ Supermercado } & Causa Humanitária & 8,24 & 1,83 & 7,41 & 8,89 & 10,00 \\
\hline & Causa Ambiental & 8,41 & 1,73 & 7,78 & 8,89 & 10,00 \\
\hline & Centrado no & 7,69 & 2,36 & 6,67 & 8,52 & 9,45 \\
\hline & Total & 8,13 & 1,98 & 7,41 & 8,89 & 10,00 \\
\hline \multirow{4}{*}{ Total } & Causa Humanitária & 8,28 & 1,82 & 7,41 & 8,89 & 10,00 \\
\hline & Causa Ambiental & 8,04 & 2,11 & 7,40 & 8,89 & 10,00 \\
\hline & $\begin{array}{l}\text { Centrado no } \\
\text { consumidor }\end{array}$ & 7,29 & 2,26 & 5,56 & 7,78 & 9,08 \\
\hline & Total & 7,85 & 2,01 & 6,67 & 8,15 & 9,26 \\
\hline
\end{tabular}

Fonte: Dados da pesquisa

Ainda pelos resultados das medidas de posição mostradas na Tabela 3, a evidência, no que concerne ao tipo de empresa, é de que os anúncios relacionados aos bancos geram uma atitude 
ligeiramente menos favorável que os anúncios relacionados aos supermercados. Embora a diferença seja pequena (como sinaliza a significância do teste), pela análise dos quartis temos a evidência de que as medidas de atitudes para os supermercados são sistematicamente maiores.

Esse resultado converge com a previsão de H5a. Embora o teste da diferença entre médias cruzadas (por tipo de empresa e estímulo) não tenha apontado variação suficiente para se anunciar uma diferença (estatística), pelas magnitudes das medidas se observa que as causas ambiental e de interesse dos consumidores geram uma atitude mais positiva quando o anúncio está associado ao supermercado, comparativamente ao que se verificou nos bancos.

Com relação ao estímulo que os anúncios promoviam em termos de preferência pela empresa, relacionados às hipóteses $\mathrm{H} 3$ e H5b, os resultados da Tabela 4 mostraram que somente por empresa há evidência de diferença significativa, em média $(\mathrm{F}(1,247 \mathrm{gl})=9,85, \mathrm{p}=0,002)$. Embora tenhamos uma indicação de que o estímulo à preferência dos consumidores pela empresa é maior, em média, quando os consumidores são expostos ao estímulo das causas socioambientais, no conjunto não temos como afirmar diferença estatística $(\mathrm{F}(2,247 \mathrm{gl})=1,29$, $\mathrm{p}=0,277$ ) por causas, o que se confirma de forma explícita nos valores de quartis (todos iguais em cada causa).

Tabela 4 - Estímulo do anúncio à preferência pela empresa

\begin{tabular}{|c|c|c|c|c|c|c|}
\hline \multirow{2}{*}{ Tipo de empresa } & \multirow{2}{*}{ Causa } & \multirow{2}{*}{ Média } & \multirow{2}{*}{$\begin{array}{l}\text { Modelo } \\
\text { padrão }\end{array}$} & \multicolumn{3}{|c|}{ Quartis } \\
\hline & & & & 1 & 2 & 3 \\
\hline \multirow{4}{*}{ Bancos } & Causa Humanitária & 6,41 & 2,11 & 5,00 & 6,50 & 8,00 \\
\hline & Causa Ambiental & 6,15 & 2,39 & 5,00 & 6,00 & 8,00 \\
\hline & Centrado no consumidor & 5,82 & 2,16 & 4,25 & 6,00 & 7,00 \\
\hline & Total & 6,13 & 2,21 & 5,00 & 6,00 & 8,00 \\
\hline \multirow{4}{*}{ Supermercado } & Causa Humanitária & 7,10 & 1,71 & 5,00 & 7,00 & 8,00 \\
\hline & Causa Ambiental & 7,07 & 1,82 & 5,00 & 8,00 & 8,00 \\
\hline & Centrado no consumidor & 6,68 & 2,16 & 5,00 & 7,00 & 8,00 \\
\hline & Total & 6,96 & 1,89 & 5,00 & 7,00 & 8,00 \\
\hline \multirow{3}{*}{ Total } & Causa Humanitária & 6,73 & 1,95 & 5,00 & 7,00 & 8,00 \\
\hline & Causa Ambiental & 6,63 & 2,15 & 5,00 & 7,00 & 8,00 \\
\hline & Centrado no consumidor & 6,22 & 2,19 & 5,00 & 7,00 & 8,00 \\
\hline
\end{tabular}




\begin{tabular}{l|l|l|l|l|l|l}
\hline Total & 6,53 & 2,10 & 5,00 & 7,00 & 8,00 \\
\hline
\end{tabular}

Fonte: Dados da pesquisa

$\mathrm{Na}$ análise cruzada de empresa e causa, novamente não tivemos evidências de diferenças nas médias $(\mathrm{F}(2,247 \mathrm{gl})=0,07, \mathrm{p}=0,935)$, ainda que observemos na magnitude das medidas (médias e quartis), especificamente em bancos, que o anúncio que enfatiza causa humanitária parece gerar maior preferência, comparativamente ao anúncio que enfatiza práticas no interesse do consumidor. Por esse resultado, fica refutada a hipótese H3.

$\mathrm{Na}$ avaliação das medidas por tipo de empresas, podemos observar que a diferença estatística atestada está mais clara nas duas medidas de tendência central (média e mediana), nas quais as medidas para os bancos são menores (no primeiro e no terceiro quartis as medidas são as mesmas). Esse resultado converge com o que foi anunciado em H5b, que foi aceita.

Por fim, em relação à variável associada à 'predisposição à recomendação' da empresa a outros consumidores que solicitassem informação, relativa às hipóteses H4 e H5c, pelos resultados da análise de variância pudemos observar a configuração de uma forte discrepância por tipo de empresa $(\mathrm{F}(1,248 \mathrm{gl})=29,10, \mathrm{p}<0,000)$, e tivemos evidência de diferenças pequenas, em nível marginal $(\mathrm{F}(2,248 \mathrm{gl})=2,90, \mathrm{p}=0,057)$, com relação aos estímulos. Sobre os estímulos, as médias mostram que a diferença está configurada pela menor predisposição à recomendação gerada nos estímulos que enfatizaram ações no interesse do consumidor, em comparação com os anúncios que traziam ações voltadas a causas socioambientais. Essas diferenças, em geral, estão repercutidas dentro de cada tipo de empresa, o que justifica a sinalização de inexistência de variação cruzada $(\mathrm{F}(2,248 \mathrm{gl})=0,743, \mathrm{p}=0,477)$. Esse resultado, que pode ser verificado na Tabela 5, refuta, portanto, a hipótese H4.

Tabela 5 - Recomendação da empresa

\begin{tabular}{c|c|c|c|c|c|c}
\hline \multirow{2}{*}{$\begin{array}{c}\text { Tipo de } \\
\text { empresa }\end{array}$} & Causa & \multirow{2}{*}{ Média } & \multirow{2}{*}{$\begin{array}{c}\text { Modelo } \\
\text { padrão }\end{array}$} & & \multicolumn{3}{|c}{ Quartis } \\
\cline { 5 - 7 } & & & $\mathbf{1}$ & $\mathbf{2}$ & $\mathbf{3}$ \\
\hline \multirow{3}{*}{ Bancos } & Causa Humanitária & 6,32 & 2,24 & 5,00 & 7,00 & 8,00 \\
& Causa Ambiental & 6,03 & 2,43 & 5,00 & 6,00 & 8,00 \\
& $\begin{array}{c}\text { Centrado no } \\
\text { consumidor }\end{array}$ & 5,38 & 1,89 & 4,50 & 5,00 & 7,00 \\
& & & & & & \\
\hline
\end{tabular}




\begin{tabular}{|c|c|c|c|c|c|c|}
\hline & Total & 5,90 & 2,21 & 5,00 & 6,00 & 7,00 \\
\hline \multirow{4}{*}{ Supermercado } & Causa Humanitária & 7,31 & 1,94 & 5,00 & 8,00 & 9,00 \\
\hline & Causa Ambiental & 7,77 & 1,90 & 7,00 & 8,00 & 9,00 \\
\hline & $\begin{array}{l}\text { Centrado no } \\
\text { consumidor }\end{array}$ & 6,97 & 2,15 & 6,00 & 7,50 & 8,00 \\
\hline & Total & 7,37 & 2,00 & 6,00 & 8,00 & 9,00 \\
\hline \multirow{4}{*}{ Total } & Causa Humanitária & 6,78 & 2,15 & 5,00 & 7,00 & 9,00 \\
\hline & Causa Ambiental & 6,94 & 2,32 & 6,00 & 7,00 & 8,25 \\
\hline & $\begin{array}{l}\text { Centrado no } \\
\text { consumidor }\end{array}$ & 6,11 & 2,15 & 5,00 & 7,00 & 8,00 \\
\hline & Total & 6,61 & 2,23 & 5,00 & 7,00 & 8,00 \\
\hline
\end{tabular}

Fonte: Dados da pesquisa

Relativo ao tipo de empresas, temos a indicação de que, conforme a previsão de H5c, a predisposição à recomendação gerada em todos os anúncios é sempre maior, em média, nos supermercados, comparativamente aos bancos. Os demais dados sinalizam que as diferenças estão evidenciadas ao longo de diferentes posições, como mostram os quartis correspondentes em cada causa e empresa.

\subsection{Discussão dos resultados}

Conforme indicado, o instrumento de coleta de dados foi dividido em duas partes. A primeira parte permitiu verificar a primeira hipótese e, pelos resultados empíricos, tivemos indicação de que, em relação à 'preferência', produtos vinculados a ações ambientais são os menos preferidos pelos respondentes, quando comparados tanto com produtos de empresas que promovem ações humanitárias quanto de ações centradas no interesse do consumidor. Já entre as iniciativas humanitárias e centradas no consumidor não houve diferenças em termos de preferência.

Ainda sem que fossem expostos aos estímulos, no que diz respeito à 'importância' atribuída aos investimentos feitos por empresas, os resultados revelaram que os respondentes somente atribuem importância de nível elevado às causas de seu interesse, ou seja, àquelas que são centradas no consumidor. A atribuição de importância às causas de interesse humanitário teve 
nível moderado; as de interesse ambiental apresentaram importância baixa. Por esses resultados, a indicação é de que os consumidores atribuem maior importância aos investimentos centrados no seu interesse do que aos investimentos vinculados a causas humanitárias ou ambientais, o que confirmou H1, e convergiu com o estudo de Pérez e Rodríguez del Bosque (2015b). A conclusão central é que, de fato, investimentos no interesse do consumidor estão mais relacionados a melhores resultados de satisfação do consumidor do que iniciativas de RSA (MCDONALD, RUDLE-THIELE, 2008), se a avaliação for de comparação direta e sem qualquer estímulo que realce a importância das ações para o consumidor.

As demais hipóteses foram verificadas a partir da exposição dos anúncios para os respondentes, considerando suas respostas a questões relacionadas aos construtos 'atitude' (relacionado às hipóteses H2 e H5a), 'preferência' (H3 e H5b) e 'predisposição a recomendar' (H4 e H5c). Assim, de acordo com os resultados quanto à atitude, é possível dizer que as ações em favor de causas humanitárias e ambientais geram atitudes mais positivas do que as causas em favor do interesse do consumidor. Esse resultado confronta a hipótese de que os consumidores desenvolvem atitudes mais favoráveis a empresas que enfatizam os investimentos no seu interesse do que por empresas que enfatizam investimentos em causas humanitárias e ambientais (H2), que não se confirma, embora contrarie a literatura (e.g. MCDONALD, LAI, 2011).

Sobre a preferência pela empresa, não tivemos variação significativa por causas, embora haja uma indicação pequena de preferências maiores geradas por anúncios de causas ambientais em relação aos anúncios que enfatizaram ações no interesse do consumidor. De todo modo, a hipótese $\mathrm{H} 3$, de que os consumidores desenvolvem maior preferência por empresas que enfatizam os investimentos no seu interesse do que por empresas que enfatizam investimentos em causas humanitárias e ambientais, também é refutada devido ao fato de a diferença observada ser em sentido contrário ao previsto. No que diz respeito à predisposição à recomendação, observamos uma variação marginal pelas causas, em que os anúncios com estímulos centrados no consumidor geravam medidas de predisposição sempre menores que os anúncios relacionados às demais causas. Aqui, mais uma vez, a hipótese de que os consumidores declaram maior predisposição a dar recomendações de empresas que enfatizam os investimentos no seu interesse, prevista em H4, foi refutada.

Os resultados das hipóteses $\mathrm{H} 1, \mathrm{H} 2, \mathrm{H} 3$ e H4 indicam que, sem que sejam expostos a estímulos de RSA, os consumidores valorizam e preferem mais investimentos em seu interesse 
(quando comparados a iniciativas que investem em causas humanitárias e ambientais). Entretanto, quando expostos aos anúncios, vemos que as respostas em relação às atitudes, às preferências e às predisposições a recomendação são, de tal modo contrárias, uma vez que as ações em favor das causas socioambientais geram medidas (de atitudes, preferências e predisposições) maiores que as iniciativas centradas no consumidor. Conclusivamente, podemos afirmar que, sem anúncios, os consumidores preferem o que está no seu interesse, o que é corroborado por outros estudos (e.g. POMERING, DOLNICAR, 2006; MCDONALD, LAI, 2011), mas que após se posicionaram diante dos anúncios, os interesses se alteram em favor de 'boas causas'.

Por fim, verificamos a avaliação dos consumidores por tipo de empresa, sob a suposição de que esses são mais favoráveis a supermercados que a bancos (H5), o que de fato se confirma mediante os resultados de que, independentemente do tipo de RSA contido nos anúncios, atitudes (H5a), preferências (H5b) e predisposições (H5c) têm sempre níveis maiores de avaliação em favor dos supermercados, comparativamente aos bancos. Esse conjunto de hipóteses, contudo, não se alinha aos resultados da pesquisa de Mattila, Hanks e Kim (2010), na qual as mensagens relacionadas ao banco apresentaram melhores níveis de atitude quando comparadas com as relacionadas à empresa de telefonia. Há convergência com o estudo experimental de Andreu, Casado-Díaz e Mattila (2015), no qual os resultados mostraram que a conscientização dos consumidores acerca de ações de RSA depende do tipo de serviço, do apelo da mensagem, e da iniciativa de RSA.

Esse resultado da hipótese H5, e sua variação em relação a estudos realizados em outros países, parece confirmar a suposição de que, no Brasil, as instituições bancárias são vistas pelos consumidores com suspeita e ceticismo, o que pode afetar a avaliação dos consumidores quando comparados com outros tipos de empresa. Ao mesmo tempo, conforme ressaltam Pérez e Rodríguez del Bosque (2014), clientes de instituições bancárias focam mais nos seus interesses, o que os tornam indiferentes a outros tipos de iniciativas de RSA.

Os resultados refletem, na verdade, que a desconfiança dos consumidores é um problema a ser solucionado pelos gestores do setor bancário, mas que seu efeito pode se dissipar mediante um gerenciamento mais ativo de sua imagem frente à sociedade. Uma análise mais profunda das alternativas nesse sentido foge do escopo desse artigo, porém naquilo a que se propôs, nosso estudo parece sinalizar algo relevante para esses gestores. De fato, considerando o conjunto das 
hipóteses, temos o entendimento de que organizações bancárias podem efetivamente ter bons resultados quando realçam seus investimentos em causas socioambientais, pois, se devidamente sensibilizados por anúncios, as respostas dos consumidores são mais favoráveis a esses tipos de causas do que a investimentos no seu interesse.

\section{CONSIDERAÇÕES FINAIS}

O propósito desse artigo foi analisar comparativamente o efeito de investimentos empresariais em ações de responsabilidade socioambiental e no interesse do consumidor, enfatizando variações e convergências dessas avaliações quando são realizadas por bancos e outros tipos de empresas. Para tanto, a partir de uma revisão da literatura, foram enunciadas cinco hipóteses centrais e três hipóteses secundárias. A primeira delas possibilitou uma verificação geral acerca de quais tipos de inciativa (humanitária, ambiental ou centrada no consumidor) eram consideradas mais importantes pelos respondentes. Por meio das demais hipóteses, correspondentes a um desenho experimental da pesquisa empírica realizada, pudemos investigar qual estímulo gerava melhores níveis de atitude, preferência e predisposição a recomendar empresas.

Como principais resultados, observamos que os consumidores dão maior preferência a investimentos empresariais no seu interesse, em detrimento dos investimentos relacionados a causas humanitárias ou ambientais. Todavia, após a sensibilização realizada pela exposição a anúncios que apresentavam estímulos referentes a esses tipos de iniciativa, os investimentos em ações de responsabilidade socioambiental geraram melhores avaliações. Isso indicou que há uma

efetiva influência do estímulo nas respostas dos consumidores, quando eles precisam se posicionar entre ações com foco em seu interesse e ações em prol de benefício socioambiental.

Considerando a construção teórica e o trabalho empírico, tivemos, no teste do primeiro conjunto de hipóteses (de H1 a H4), a resposta ao primeiro objetivo desse estudo (que foi analisar a avaliação dos consumidores acerca de investimentos no seu interesse ou em iniciativas de RSA). O teste da última hipótese (H5, que teve três sub hipóteses) possibilitou alcançar nosso segundo objetivo, que era verificar possíveis diferenças na avaliação dos consumidores entre empresas bancárias ou de outros tipos (aqui utilizamos os supermercados como referencial de comparação). 
Esses resultados contribuem para o corpo teórico sobre efeitos comparativos das ações de responsabilidade socioambiental, por tipo de empresa, com foco naquelas realizadas por instituições bancárias, tema que tem apresentado bastante interesse da comunidade acadêmica. Quanto às implicações práticas, entendemos que essa pesquisa evidencia quais tipos de iniciativa, dentre as utilizadas no nosso estudo, são mais valorizadas pelos consumidores e o efeito do estímulo publicitário na formação de atitudes, preferências e predisposições. Assim, ao considerarmos as empresas dos tipos aqui avaliados, em especial os bancos, que são objeto da defenestração pública, principalmente no contexto do debate político e eleitoral, há indicação da relevância dos investimentos e da comunicação adequados sobre as ações de RSA.

Por fim, reconhecemos que a pesquisa sofreu uma limitação no plano amostral, na medida em que se restringiu ao público de determinada região. Assim, embora nosso estudo tenha se baseado em uma amostra com boa heterogeneidade, sugerimos que sejam realizados outros estudos em outras regiões que possam verificar se a avaliação dos consumidores se comporta da mesma maneira ou se há algum tipo de variação por localidade, por exemplo.

\section{REFERÊNCIAS}

ANDREU, L.; CASADO-DÍAZ, A. B.; MATTILA, A. S. Effects of message appeal and service type in RSA communication strategies. Journal of Business Research, Amsterdam, v. 68, n. 7, p. 1488-1495, 2015.

BHATTACHARYA, C. B.; SEN, S. Doing Better at Doing Good: When, Why, and How Consumers Respond to Corporate Social Initiatives. California Management Review, Berkeley, v. 47 n. 1, p. 9-24, 2004.

BHATTACHARYA, C. B.; KORSCHUN, D.; SEN, S. Strengthening stakeholder-company relationships through mutually beneficial corporate social responsibility initiatives. Journal of Business Ethics, New York, v. 85, n. 2, p. 257-272, 2009.

CARROLL, A. B. The pyramid of corporate social responsibility: Toward the moral management of organizational stakeholders. Business Horizons, Amsterdam, v. 34, n. 4, p. 39-48, 1991.

CONOVER, W. J. Practical nonparametric statistics. 2. ed. New York: Wiley, 1980.

COSTA, F. J. Mensuração e desenvolvimento de escalas: aplicações em Administração. Rio de Janeiro: Ciência Moderna, 2011. 
CRISÓSTOMO, V. L.; FREIRE, F. S.; SOARES, P. M. Uma análise comparativa da responsabilidade social corporativa entre o setor bancário e outros no Brasil. Contabilidade Vista \& Revista, Belo Horizonte, v. 23, n. 4, p. 103-128, 2012.

DU, S.; BHATTACHARYA, C. B.; SEN, S. Maximizing business returns to corporate social responsibility (CSR): The role of CSR communication. International Journal of Management Reviews, Hoboken, v. 12, n. 1, p. 8-19, 2010.

HAIR JR., J. F. et al. Análise multivariada de dados. 6. ed. São Paulo: Bookman, 2009.

KHAN, S. et al. Do corporate social responsibility initiatives favorable for banks? Customer's perceptions. Business and Economic Research, Bursa, v. 4, n. 1, p. 230-247, 2014.

KHAN, Z.; FERGUSON, D.; PÉREZ, A. Customer responses to CSR in the Pakistani banking industry. International Journal of Bank Marketing, Bingley, v. 33, n. 4, p. 471-493, 2015.

LATTIN, J.; CARROL, J. D.; GREEN, P. E. Análise de dados multivariados. São Paulo: Cengage Learning, 2011.

MATTILA, A. S.; HANKS, L.; KIM, E. E. K. The impact of company type and corporate social responsibility messaging on consumer perceptions. Journal of Financial Services Marketing, New York, v. 15, n. 2, p. 126-135, 2010.

MCDONALD, L. M.; LAI, C. H. Impact of corporate social responsibility initiatives on Taiwanese banking customers. International Journal of Bank Marketing, Bingley, v. 29, n. 1, p. 50-63, 2011.

MCDONALD, L. M.; RUNDLE-THIELE, S. Corporate social responsibility and bank customer satisfaction: a research agenda. International Journal of Bank Marketing, Bingley, v. 26, n. 3, p. 170-182, 2008.

PELOZA, J.; SHANG, J. How can corporate social responsibility activities create value for stakeholders? A systematic review. Journal of the Academy of Marketing Science, New York, v. 39, n. 1, p. 117-135, 2011.

PÉREZ, A.; RODRÍGUEZ DEL BOSQUE, I. The role of CSR in the corporate identity of banking service providers. Journal of Business Ethics, New York, v. 108, n. 2, p. 145-166, 2012.

PÉREZ, A.; RODRÍGUEZ DEL BOSQUE, I. Customer RSA expectations in the banking industry. International Journal of Bank Marketing, Bingley, v. 32, n. 3, p. 223-244, 2014.

PÉREZ, A.; RODRÍGUEZ DEL BOSQUE, I. How customers construct corporate social responsibility images: Testing the moderating role of demographic characteristics. BRQ Business Research Quarterly, Amsterdam, v. 18, n. 2, p. 127-141, 2015a. 
PÉREZ, A.; RODRÍGUEZ DEL BOSQUE, I. Corporate social responsibility and customer loyalty: exploring the role of identification, satisfaction and type of company. Journal of Services Marketing, Bingley, v. 29, n. 1, p. 15-25, $2015 \mathrm{~b}$.

POMERING, A.; DOLNICAR, S. Customers' sensitivity to different measures of corporate social responsibility in the Australian banking sector. In: ANZMAC (Australia and New Zealand Marketing Academy Conference), 2006, Brisbane. Proceedings... Brisbane, Queensland: Queensland University of Technology, dec. 2006. CD ROM.

POOLTHONG, Y.; MANDHACHITARA, R. Customer expectations of CSR, perceived service quality and brand effect in Thai retail banking. International Journal of Bank Marketing, Bingley, v. 27, n. 6, p. 408-427, 2009.

SEN, S.; BHATTACHARYA, C. B.; KORSCHUN, D. The role of corporate social responsibility in strengthening multiple stakeholder relationships: A field experiment. Journal of the Academy of Marketing Science, New York, v. 34, n. 2, p. 158-166, 2006.

SCHARF, E. R.; FERNANDES, J.; KORMANN, B. D. Corporate social responsibility to build strong Brazilian bank brand. International Journal of Bank Marketing, Bingley, v. 30, n. 6, p. 436-451, 2012.

SCHWARTZ, M.; CARROLL, A. Integrating and unifying competing and complementary frameworks: the search for a common core in the business and society field. Business and Society, Thousand Oaks, v. 47, n. 2, p. 148-186, 2008.

VAALAND, T. I.; HEIDE, M.; GRØNHAUG, K. Corporate social responsibility: investigating theory and research in the marketing context. European Journal of Marketing, Bingley, v. 42, n. 9/10, p. 927-953, 2008.

YOON, Y.; GÜRHAN-CANLI, Z.; SCHWARZ, N. The effect of corporate social responsibility (CSR) activities on companies with bad reputations. Journal of Consumer Psychology, Amsterdam, v. 16, n. 4, p. 377-390, 2006. 